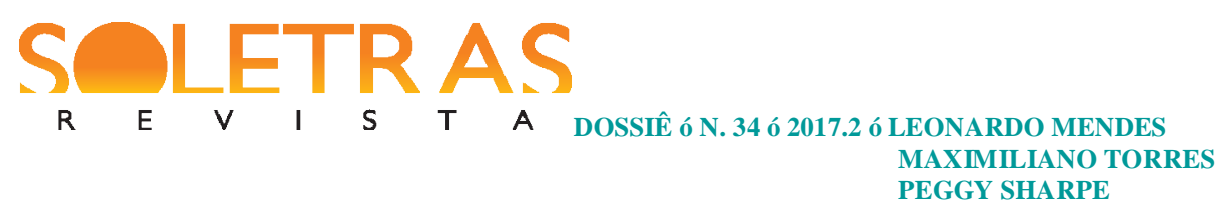

\title{
ESCRITORES ESQUECIDOS DO SÉCULO XIX
}

\begin{abstract}
APRESENTAÇÃO
A proposta do presente dossiê surgiu do desejo da elaboração de um espaço de divulgação das pesquisas acadêmicas originais sobre autores desconhecidos (ou pouco conhecidos) ao ñongo século XIXò (1789-1914), de qualquer nacionalidade. Com grande satisfação - e aqui já registramos nossa gratidão pelo reconhecimento do projeto - recebemos em torno de trinta submissões.

O conjunto dos vinte artigos científicos selecionados traz uma amostra da diversidade de caminhos possíveis de desaparecimento de escritores oitocentistas. Alguns textos especulam sobre as razões do esquecimento, enquanto outros, não menos importantes, se atêm à história do escritor esquecido, investigando algum aspecto das obras. Os textos estão organizados a partir de uma combinação de critérios: temporal, genérico, geográfico e geracional. No intuito de fomentar a reflexão sobre as razões e processos de esquecimento literário, revelados pelo conjunto dos textos, faremos um comentário breve sobre cada um dos artigos e seus respectivos escritores.

Em ñPaula Brito, escritor esquecidoò Lucia Granja e Jakeline Longo Porto estudam a pouca conhecida narrativa curta de ficção de Francisco de Paula Brito (1809-1861), destacado editor e jornalista carioca da primeira metade do século XIX, considerado o primeiro empresário negro brasileiro, tradutor e autor de poemas e contos. As autoras se detêm no estudo de três contos-folhetim publicados no Jornal do Commercio, no Rio de Janeiro, em 1839: ñRevelação póstumaò, ñA mãe-irmã (história contemporânea)ò e ño enjeitadoò, que podem ser considerados precursores do conto no Brasil. Neles, as autoras encontram temas e formas que se tornariam marcas da ficção brasileira posterior, como o patriarcalismo, o escravismo e a técnica da narrativa epistolar, reconhecíveis em Joaquim Manuel de Macedo, Machado de Assis e Aluísio Azevedo. Destacam, ainda, a presença no conto ñA mãe-irmãò da heroína Alzira, a primeira morena bonita da literatura brasileira.
\end{abstract}

Valéria Cristina Bezerra, em ñSalvador de Mendonça: um polígrafo entre as letras nacionais e estrangeirasò, revela outro escritor brasileiro oitocentista esquecido. Natural de

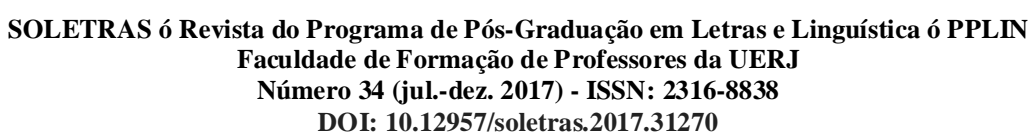




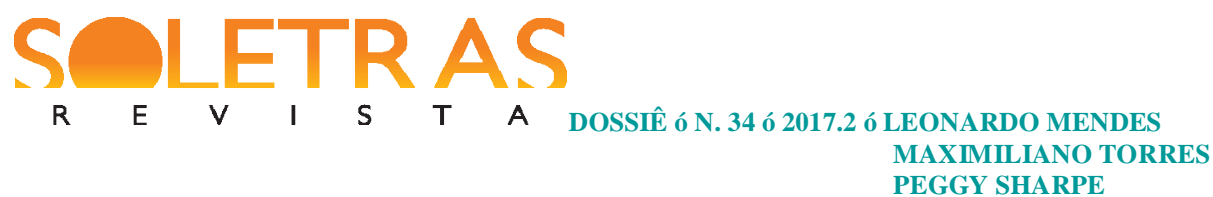

Itaboraí (RJ), professor, crítico, tradutor, romancista e jornalista, Salvador de Mendonça (18411913) foi um dos fundadores da Academia Brasileira de Letras, em 1897, e encarnou a figura do homem de letras como polígrafo, capaz de atuar em várias frentes e capacidades. Ao lado de José de Alencar, participou das batalhas pelo estabelecimento de uma literatura nacional, ao mesmo tempo em que traduzia romances franceses. Em 1875, publicou seu único romance, Marabá, cujo título remetia à ama mestiça do protagonista Agenor, por quem a jovem Lucia se apaixona. O casal vive uma história de amor, traição e morte, combinando temas da literatura estrangeira $\mathrm{i}$ notadamente A dama das camélias (1848), de Dumas Filho ï, com o cuidado em retratar a miscigenação, os costumes e a cor locais.

Em ñóA fada do mysterioô de Félix Xavier da Cunha: um conto fantástico perdido no século XIXò, Abílio Aparecido Francisco Junior e Adilson Santos se propõem estudar o conto do título de forma a lançar luz sobre um autor esquecido e, ao mesmo tempo, um gênero pouco estudado: a literatura fantástica. Natural de Porto Alegre, Felix Xavier da Cunha (1833-1865) foi contemporâneo da geração ultrarromântica e companheiro de Álvares de Azevedo na Faculdade de Direito de São Paulo, na década de 1850, quando colaborou com vários periódicos, entre os quais $O$ Acayaba, no qual publicou o conto ñA fada do mysterioò (1853). Ambientado em cemitérios e mausoléus, o conto narra a história trágica de um amor não correspondido. Nele os autores identificam os ideais mórbidos e sentimentalismos extremos do ultrarromantismo, assim como marcas de ñantinomiaò, dado o caráter paradoxal e espelhado da narrativa, resultando na incerteza como elemento essencial do gênero fantástico.

Fernando Monteiro de Barros e Márcio Alessandro de Oliveira, no artigo ño gótico brasileiro na poesia de Carlos Ferreiraò, revelam outro escritor oitocentista do Rio Grande do Sul, com predileções góticas. Assim como a literatura fantástica, o gótico foi ignorado (ou desvalorizado) pela historiografia tradicional. Carlos Ferreira (1844-1913) também era de Porto Alegre, foi um dos nossos primeiros baudelairianos e fez a transição do romantismo para o parnasianismo, chegando a usar tintas decadentistas. O estudo se concentra em dois poemas publicados no volume Redivivas (1881) ï ñA Baronesaò e a ñA escravaò ï ñdois retratos antitéticos da mulher no Brasil monárquico e escravocrataò, nos quais os autores identificam

SOLETRAS ï Revista do Programa de Pós-Graduação em Letras e Linguística ï PPLIN

Faculdade de Formação de Professores da UERJ

Número 34 (jul.-dez. 2017) - ISSN: 2316-8838

DOI: $10.12957 /$ soletras.2017.31270 


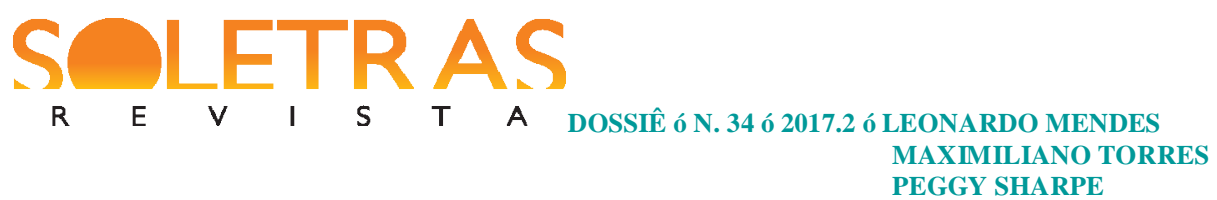

marcas fundadoras do gótico brasileiro. Os conflitos e personagens têm como pano de fundo o latifúndio escravista, lócus essencial para toda a literatura brasileira do século XIX. Os autores entendem o gótico brasileiro como um procedimento legítimo de antropofagia cultural.

No estudo de Júlio França e Ana Paula Araújo dos Santos, ño páter-famílias como vilão gótico em Úrsula, de Maria Firmina dos Reisò, continuamos no subvalorizado gênero gótico, mas agora de autoria feminina. Maria Firmina dos Reis (1822-1917) era natural do Maranhão e pertence à polpuda lista de escritoras brasileiras oitocentistas esquecidas e resgatadas por grupos de pesquisa em várias universidades brasileiras, a partir do final do século XX. Para os autores, Úrsula (1859) pode ser considerado um exemplo do gótico feminino, vertente que usa ñas convenções góticas como um mecanismo para explorar, na ficção, as insatisfações, ansiedades e conflitos vivenciados pela mulher em um mundo dominado por valores patriarcaisò Nessas narrativas, o páter-família aparece como o principal antagonista. Ao criticar a condição feminina na sociedade patriarcal e escravista brasileira, o romance Úrsula, por muito tempo esquecido, oferece importante contribuição à vertente do gótico feminino entre nós.

No artigo ñA tradição alternativa do drama alemão: Friedrich Hebbel e seus precursoresò, Felipe Vale da Silva estuda o caso do escritor eclipsado pelos pupilos mais célebres (Kafka e Ibsen). Natural de Wesselburen, Christian Friedrich Hebbel (1813-1863) foi um dos introdutores do conto na Alemanha e autor da versão teatral mais encenada da mitologia nórdica dôOs Nibelungos (1862). O autor destaca o drama Maria Madalena (1844), associado a uma tradição alternativa pouco lembrada da dramaturgia alemã, que retoma certas convenções do Sturm und Drang. Na sucessão de infortúnios que leva os dois filhos do marceneiro Anton ï representantes da nova geração ï à morte ou à prisão, Hebbel faz uma crítica ao ñmundo moldado pela lógica do capital, patriotismo e valores burgueses, sem tentar mascarar seus efeitos colateraisò Para o autor, Friedrich Hebbel emerge como o restaurador de uma tradição (passada e futura) do drama alemão que usa o teatro como mecanismo de crítica ao presente.

Gerson Roberto Neumann e Claudia Fernanda Pavan, em ñRéquiem para Gerstäcker, o inquieto solitárioò, contam a história de outro escritor alemão oitocentista esquecido, sendo que este escreveu três livros sobre o Brasil. Autor de mais de 40 obras, Friedrich Gerstäcker (1816-

SOLETRAS ï Revista do Programa de Pós-Graduação em Letras e Linguística ï PPLIN

Faculdade de Formação de Professores da UERJ

Número 34 (jul.-dez. 2017) - ISSN: 2316-8838

DOI: $10.12957 /$ soletras.2017.31270 


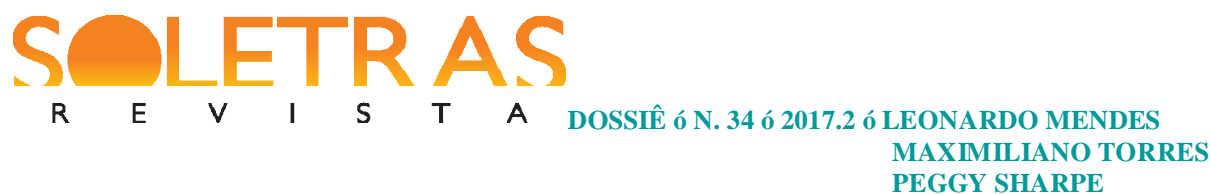

1872) nasceu em Hamburgo. Foi pioneiro da literatura de aventura e um dos escritores mais bem sucedidos de seu tempo, citado por Walter Benjamin no ensaio ñO narradorò De forma sóbria, sua obra apontava as vantagens da emigração alemã para as Américas, descrevia os territórios e alertava seus conterrâneos sobre os perigos da empreitada. Tal visão aparece nos livros sobre a colonização alemã no Brasil. No romance A Colônia. Cenas da vida no Brasil (1862), traduzido e publicado pela Editora Gradiva, em 2016, Gerstäcker descreve a vida dos habitantes de uma colônia alemã fictícia em Santa Catarina. Como comprovam os autores, a importância do escritor para o ñpolissistema literário brasileiroòé indiscutível.

No estudo ñâm órilhante congressoô escritoras portuguesas no projeto de Antônio Feliciano de Castilho para sua versão de Os Fastos ovidianosò Eduardo da Cruz abre a seção dos escritores portugueses. $\mathrm{O}$ autor se concentra na correspondência entre Castilho e sete escritoras convidadas por ele para redigir notas explicativas na edição de sua tradução de Ovídio, entre 1859 e 1860. As cartas revelam mulheres letradas de Lisboa, Porto e Ilha da Madeira, que mantinham salões literários e lutavam para escrever e publicar num ambiente hostil. Entre as escritoras próximas a Castilho, a ñmestra régiaò Maria José da Silva Canuto é especialmente interessante. Ela vivia ocupadíssima com a atividade docente, publicava versos em periódicos, morava só e traduzia literatura francesa. Algumas autoras estavam em franco processo de profissionalização. Como conclui o autor, as cartas revelam que no século XIX o número de escritoras em Portugal era maior do que diz a historiografia.

Outra escritora portuguesa esquecida do período é estudada por Conceição Flores em ñóMeditaçõesò autobiográficas de Ana Plácidoò. A autora se concentra na obra do título, que faz parte do livro Luz coada por ferros (1863), escrito por Ana Plácido (1831-1895) enquanto se encontrava presa por adultério, entre 1860 e 1861. A obra conta a trajetória tradicional da moça casada contra a vontade com um homem mais velho e rico, com quem vive 8 míseros anos, até abandoná-lo, com grande escândalo, para viver com o escritor Camilo Castelo Branco. Em ñMeditaçõesò, a escritora denuncia a hipocrisia dos inimigos, coloca em xeque o papel da mulher como dona de casa e critica a dificuldade de inserção de qualquer escritora naquela sociedade. Depois da saída prisão, Ana Plácido colaborou com periódicos do Porto, publicou uma peça de 


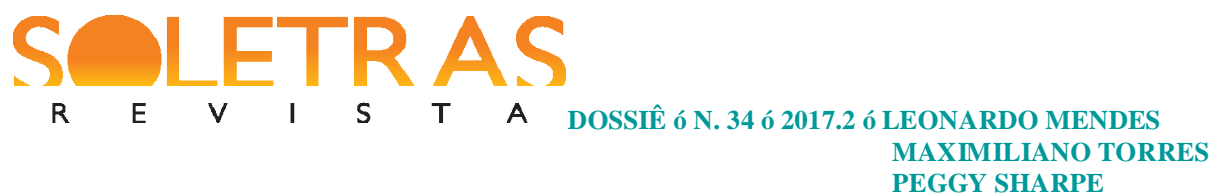

teatro e um romance, Herança de lágrimas (1871), com o pseudônimo ñLopo de Souzaò. Entretanto, como tantas outras mulheres das letras, foi eclipsada pela escrita e pelo nome do marido famoso.

Em ñó ma literatura verdadeiramente femininaò: Ana de Castro Osório e a germinação do pensamento feminista em Portugal no século XIXò, Jorge Vicente Valentim se concentra em duas palestras da escritora portuguesa Ana de Castro Osório (1872-1935) ï ñO novo idealismo da raça na moderna literatura portuguesaòe ñA Mulher de Portugal e do Brasilòï lidas por ela no Brasil, em 1922, por ocasião do centenário da Independência. No seu tempo, a escritora publicou literatura infanto-juvenil, dramaturgia, romances, contos, palestras e textos de teor didáticopedagógico. $\mathrm{O}$ autor encontra nas duas conferências possíveis convergências com ideias feministas que começavam a pipocar em outros países da Europa, na virada do século XIX para o $\mathrm{XX}$, especialmente no destaque dado ao papel da mulher na construção e manutenção do Império português. Para o autor, Ana de Castro Osório pode ser considerada uma disseminadora de ideias feministas, tanto em solo português quanto brasileiro.

Célia Sousa Vieira fecha a seção de portugueses esquecidos com o estudo ñosé Maria da Cunha Seixas (1836-1895), filósofo e crítico literárioò. No segundo oitocentos, nas batalhas pelo naturalismo e o positivismo, Cunha Seixas resistiu aos modismos do tempo, mesmo ao preço do anonimato. Nascido em Trevões, advogado e filósofo, autor de vários volumes ensaísticos publicados nas décadas de 70 e 80 , o escritor trabalhou pela harmonização entre a necessária modernização científica e a refundição de um novo idealismo. Embora reconhecesse a verdade do ñomem fisiológicoò achava que a ciência não devia restringir seu campo de conhecimento ao mundo sensível e mensurável, admitindo outra dimensão ñincógnita e inexplicávelò (para ele inegável) da existência humana. Como mostra a autora, na vertente de um ñpositivismo moderadoò pouco estudado pela historiografia, os textos de teoria e de crítica literária de Cunha Seixas ocupam lugar de destaque.

Em ñLéon Bloy contra seu tempoò, Régis Mikail Abud Filho estuda o único autor francês do dossiê. Católico fervoroso no século do cientificismo, ñum dos maiores detratores do longo século XIXò, Léon Bloy (1846-1917) foi um escritor deliberadamente ignorado pelos pares e pela

SOLETRAS ï Revista do Programa de Pós-Graduação em Letras e Linguística Ï PPLIN

Faculdade de Formação de Professores da UERJ

Número 34 (jul.-dez. 2017) - ISSN: 2316-8838

DOI: $10.12957 /$ soletras.2017.31270 


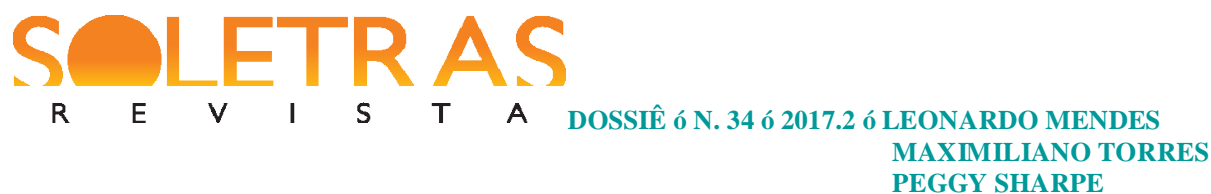

posteridade, tomado como inimigo por vários literatos (Zola, Maupassant e Huysmans). Também atacou a classe burguesa e seus valores, intrinsecamente associados ao materialismo do período, o que dificultou ainda mais a sua carreira. Sua verve panfletária era mordaz e escatológica, alinhada à sua visão de catolicismo extremado. Com fama de invendável, nunca conseguiu viver de literatura. Passou então a mendigar, atividade da qual não se envergonhava. Apesar das dificuldades, Bloy logrou publicar contos, ensaios e romances, como Le Désespéré (1887) e La femme pauvre (1897), nos quais subverte o modelo narrativo do realismo então dominante.

No estudo ñNarcisa Amália, poeta esquecida do século XIXò, Anna Faedrich abre a seção dos escritores brasileiros do segundo Oitocentos. Poeta romântica, natural de São João da Barra (RJ), Narcisa Amália (1852-1924) foi uma importante intelectual brasileira do século XIX: feminista, republicana, abolicionista, tradutora do francês e jornalista profissional. Publicou aos vinte anos um único livro de poemas, Nebulosas (1872), que ganhou resenha positiva de Machado de Assis. A obra reúne poemas anteriormente publicados em jornais, com bom domínio da forma e temática romântica, como o nacionalismo, a exaltação da natureza e a saudade da terra e da infância. O estudo destaca a faceta abolicionista da poeta, como em ño Africano e o Poetaò, no qual dialoga com a geração condoeira. Narcisa Amália fez parte do grupo seleto de escritoras que conseguiu se inserir num campo literário dominado por homens. Em vida, não passou despercebida, mas também foi esquecida pela seletiva historiografia literária.

Irineu Eduardo Jones Corrêa, em ñA poesia excêntrica de Medeiros e Albuquerque: o decadentismo na Academiaò, aborda a pouco estudada poesia decadentista brasileira do fim do século XIX. O estudo se concentra em dois livros ï Pecados e Canções da decadência, ambos de 1889 ï do recifense Joaquim José Medeiros e Albuquerque (1867-1934), outro fundador da ABL que foi esquecido. Baseando-se na leitura de Rimbaud, Verlaine, Baudelaire, entre outros, o poeta integrava o debate estético do seu tempo e encarnava a figura do artista como ñécrivain-dandyò: marginal, pessimista e bem vestido. Em poemas como ñA uma pecadoraò Medeiros e Albuquerque traz para o plano poético a r̃beleza do malò, numa elaboração convergente com Les fleurs du mal (1857), de Baudelaire. Como mostra o autor, os decadentistas trouxeram para a 


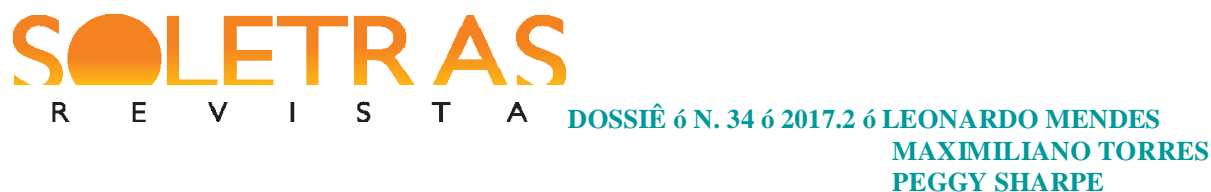

literatura ña doença, a perversão e a maldadeò trabalhadas como objeto final da arte, o que muito chocou o público, os pares e a historiografia.

Em ñImpasses e negociações na prosa de Domício da Gamaò, Haroldo Ceravolo Sereza estuda a pequena obra de um escritor cuja vida literária foi obscurecida pela atividade políticodiplomática. Natural de Maricá (RJ), Domício da Gama (1862-1925) também foi um dos fundadores da ABL e publicou dois livros de contos, Contos a meia tinta (1891) e Histórias Curtas (1901). Alguns apontam semelhanças entre Domício da Gama e Machado de Assis, enquanto outros classificam sua prosa como ñmpressionismo literárioò, em que figuram Marcel Proust e Henry James. Membro da geração de escritores que batalhou pela república e depois se decepcionou com o resultado, Gama tematiza em sua ficção justamente a distância entre os projetos e as realizações ï daí os impasses a que se refere o título do artigo. O estudo da sua correspondência revela as boas relações com escritores e políticos brasileiros de peso. Contudo, a força positiva de tais relações não o impediu de cair no ostracismo.

Da mesma geração que Medeiros e Albuquerque e Domício da Gama, e, como eles, membro do grupo fundador da ABL, o escritor carioca Pedro Rabelo (1868-1905) é estudado por Leonardo Mendes e Riane Avelino Dias em ñPedro Rabelo, escritor naturalistaò. Como outros escritores de sua época, Rabelo foi jornalista com passagem pelos principais periódicos da capital, na qualidade de redator e cronista. Publicou em vida quatro livros: Ópera lírica (1893), livro de poesia; A alma alheia (1895), sua principal obra, um livro de contos; Filhotadas (1897) e Casos alegres: histórias para sorumbáticos (1905), que reúnem textos humorísticos publicados em periódicos e assinados sob o pseudônimo ñPierrotò A opinião mais conhecida sobre seus contos era que imitavam o estilo de Machado de Assis, de quem era discípulo. Chamado de ñescritor naturalistaò pelos pares, Pedro Rabelo pode ser incluído no rol dos naturalistas brasileiros, na vertente pouco conhecida do ñnaturalismo da desilusãoò.

Em ñFigueiredo Pimentel: Contos da Carochinha e o nascimento da literatura infantil abrasileirada no final do século XIXò, Cristina Rothier Duarte e Daniela Maria Segabinazu abordam um escritor que ainda pode ser considerado ñesquecidoò. Natural de Macaé (RJ), Alberto Figueiredo Pimentel (1869-1914) ganhou fama de autor pornográfico quando estreou

SOLETRAS ï Revista do Programa de Pós-Graduação em Letras e Linguística Ï PPLIN

Faculdade de Formação de Professores da UERJ

Número 34 (jul.-dez. 2017) - ISSN: 2316-8838

DOI: $10.12957 /$ soletras.2017.31270 


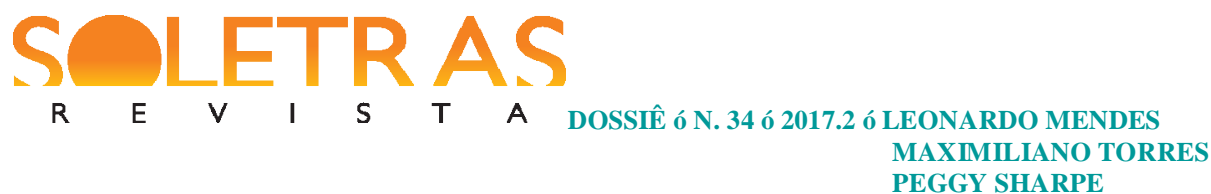

com o romance naturalista $O$ aborto (1893). Ainda publicaria outros romances da escola, poesias parnasianas e crônicas nos jornais, com destaque para a coluna ño Binóculoò na década de 1900. Ganhou fama como introdutor da literatura para a infância no Brasil, com a publicação de vários títulos bem-sucedidos ao longo dos anos. Em Contos da Carochinha (1894), como mostram as autoras, ao adaptar histórias de Charles Perrault e dos Irmãos Grimm a contextos locais e criar suas próprias histórias, Figueiredo Pimentel inventou uma literatura infantil ñabrasileiradaò, ganhando milhares de leitores à época.

Celina Maria Moreira de Mello e Zadig Mariano Figueira Gama estudam outro escritor esquecido da geração de Figueiredo Pimentel. Em ñLuiz Gastão dâEscragnolle Dória: um polígrafo das Letras brasileirasò, os autores analisam as diversas frentes em que o escritor atuou ao longo de sua trajetória. Nascido no Rio de Janeiro, advogado pela Faculdade de Direito de São Paulo, jornalista, professor e historiador, Escragnolle Dória (1869-1948) publicou a coletânea de contos Dor (1903), além de inúmeras contribuições em vários gêneros textuais a periódicos de todas as regiões do país. Na sua trajetória destaca-se a correspondência com o escritor naturalista francês Edmond de Goncourt, de quem se tornou o primeiro tradutor brasileiro, publicando em 1891 uma tradução do romance Soeur Philomène (1861) no folhetim do Jornal do Commercio. Como mostra a pesquisa dos autores, Escragnolle Dória é outro polígrafo brasileiro esquecido.

No estudo ñPelo buraco da fechadura: autores e obras da literatura pornográfica lusobrasileira (1890-1912)ò, Natanael Duarte Azevedo resgata um tipo de escrita silenciada pela história da literatura: a pornografia, chamada no período de ñeitura para homensò. No Brasil, o final do século XIX assistiu a uma expansão da imprensa e do mercado livreiro, com destaque para o aumento da produção e circulação de literatura licenciosa. $\mathrm{O}$ autor mostra como a escrita pornográfica estava associada à imprensa satírica, em jornais como $O$ Rio $N u, O$ Riso e $O$ Coió, que incluíam imagens de nu artístico. No formato de livro, um campeão de vendas foi o escritor português Alfredo Gallis (1859-1910), que publicou com o pseudônimo ñRabelaisò inúmeros ñivros para homensò, entre os quais A História de Cada Uma, analisada pelo autor. Destaca ainda os poemas de Laurindo Rebelo (1826-1864) como precursores da literatura erótica no Brasil. O estudo é um convite para buscar outros ñimoraisò esquecidos.

SOLETRAS ï Revista do Programa de Pós-Graduação em Letras e Linguística İ PPLIN

Faculdade de Formação de Professores da UERJ

Número 34 (jul.-dez. 2017) - ISSN: 2316-8838

DOI: 10.12957/soletras.2017.31270 


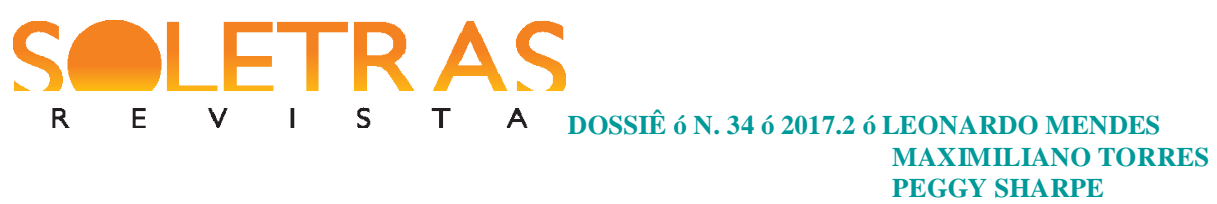

Por fim, no artigo ñMulheres descobertas no lixoò, Lúcia Bettencourt fecha o dossiê com uma reflexão sobre a memória, o apagamento e o esquecimento, especialmente de mulheres do século XIX. Implícita no título, a metáfora do descarte serve como ponto de partida para a autora lembrar mulheres oitocentistas ativas no seu tempo, mas esquecidas, como Maria Felipa de Oliveira, que lutou nas guerras de Independência na Bahia, e Luísa Mahin, mãe do escritor abolicionista Luís Gama. No rol das escritoras do período, lembra alguns nomes estudados neste dossiê, como Maria Firmina dos Reis e Narcisa Amália, e outras ausentes, como Emília Moncorvo Bandeira de Melo (1852-1910), Maria Benedita Bormann (1853-1895) e, a hoje mais conhecida, Julia Lopes de Almeida (1862-1934), que enfrentavam inúmeras barreiras para escrever e publicar. A autora destaca a importância de ouvir vozes silenciadas do passado e de compreender as razões do seu apagamento.

Os elencados artigos científicos dessa coletânea representam uma pequena parte de um campo de pesquisa em expansão que visa remexer os escombros de uma história literária, unilateral e monolítica, que privilegiou determinados autores e suas obras em detrimento de outros. Em suas conjecturas sobre o conceito de história, Walter Benjamin nos lembra que jamais ñouve um monumento de cultura que também não fosse um monumento de barbárieò (BENJAMIN, 1987, p. 222) e que, se não há isenção da barbárie na cultura, não haverá tampouco em seu processo de transmissão. Com isso, numa crítica à teoria social democrata e à teoria do historicismo, o filósofo alemão considera de extrema importância se pensar a história a contrapelo; por outras visões, por outros discursos. Ao contrário da tradição que, ao dar voz para uma estreita parcela - a dos ñvencedoresò -, valorizou a injustiça, o mutismo e o esquecimento. Nesse sentido, indaga que o ñpassado traz consigo um índice misterioso, que o impele à redenção. Pois não somos tocados por um sopro do ar que foi respirado antes? Não existem, nas vozes que escutamos, ecos de vozes que emudeceram?ò(BENJAMIN, 1987, p. 223).

Através do resgate desses inúmeros nomes soterrados pelo cânone, o dossiê ñEscritores esquecidos do século XIXò, possibilita não só reescrevermos uma historiografia imposta por um discurso autoritário e excludente, mas, refletir sobre as várias formas de construção da cultura e, principalmente, sobre qual o nosso papel de pesquisadores de literatura; aqueles que buscam nos

SOLETRAS ï Revista do Programa de Pós-Graduação em Letras e Linguística Ï PPLIN

Faculdade de Formação de Professores da UERJ

Número 34 (jul.-dez. 2017) - ISSN: 2316-8838

DOI: 10.12957/soletras.2017.31270 


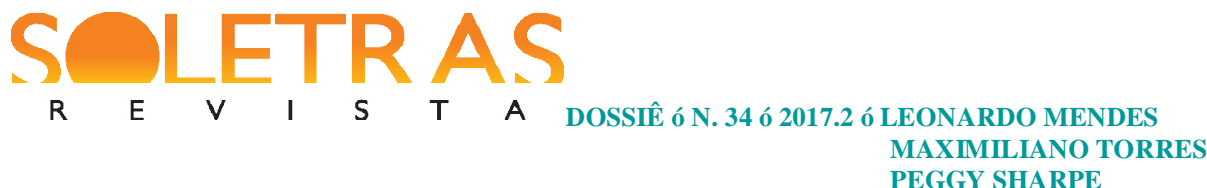

escritos do passado um diálogo (ou ecos, como quis Benjamin), a todo o tempo, com o presente. Afinal, como alerta Nietzsche, em ñVantagens e desvantagens da história para a vidaò: ñPrecisamos da história, mas não como precisam dela os ociosos que passeiam no jardim da ciênciaÒ(BENJAMIN, 1987, p. 228).

\section{Referências}

BENJAMIN, Walter. Magia e técnica, arte e política. Trad. Sérgio Paulo Rouanet. 3ed. São Paulo: Brasiliense, 1987.

Organizadores

Leonardo Mendes Maximiliano Torres

Peggy Sharpe 